\section{Protamine-containing insulins are strong risk factors, and human insulin analogues are possible risk factors for insulin autoantibody: case-control study}

Hiroyuki Kinoshita, ${ }^{1}$ Mutsuko Yasuda, ${ }^{1}$
Kaoru Nagasawa,2 Fumiatsu Yakushiji1

1Department of Internal Medicine, Tokyo Metropolitan Bokutoh Hospital, Tokyo; 2Department of Endocrinology and Metabolism, Toranomon Hospital, Tokyo, Japan

\section{Abstract}

Insulin autoantibody is known to cause fluctuation of blood glucose. We examined whether medications for diabetes are risk factors for insulin autoantibody. Especially, we examined the associations between types of insulin and insulin autoantibody. We performed a case-control study. From April 2005 to March 2010, insulin autoantibody was measured 273 times in 217 patients in our hospital. Insulin autoantibody was positive (greater than 10\%) 53 times in 19 patients (case), and was negative 220 times in 198 patients (control). Oral hypoglycemic agents were not risk factors for insulin autoantibody; the odds ratio was 0.0 . In contrast, insulin use was a significant risk factor for insulin autoantibody; the odds ratio (95\% confidence interval) was 56.3 (7.3-432.5). As for the types of insulin and insulin autoantibody, human insulins without protamine were not risk factors; the odds ratio was 0.0. For protamine-containing insulins, the odds ratio and adjusted odds ratio (adjusted by age, gender, and disease: type 1 diabetes mellitus, type 2 diabetes mellitus, and no diabetes) were 35.3 (9.6-129.5) and 29.6 (7.6115.4), respectively. For Aspart-containing insulins, they were 6.2 (2.2-17.9) and 3.8 (1.2$12.0)$, respectively. For Glargine, they were 3.2 $(0.6-16.7)$ and $1.3(0.2-8.3)$, respectively. To decrease the problem of insulin antibody, avoiding the use of protamine-containing insulins and avoiding the use of human insulin analogues might be preferable for the patients with diabetes.

\section{Introduction}

Insulin autoantibody is known to cause fluctuation of blood glucose and insulin injection is one of the risk factors for producing insulin autoantibody. ${ }^{1-4}$ Prior to the 1980 s, virtually all patients that used insulin had insulin autoantibody. ${ }^{3}$ However, during the 1980 s and thereafter, insulin autoantibody was decreased as a consequence of the improvements in the purity of insulin preparations and the development of human insulin. 3,5

To date, some insulin preparations are supplemented with additives, such as protamine, to make the insulin long-acting. However, protamine-containing insulins can cause production of insulin autoantibody.6,7 In addition, after the 1990s, many human insulin analogues with amino acid substitution(s) were developed. However, human insulin analogues can also cause insulin autoantibody production. ${ }^{8}$ There have been some studies about the various types of insulin and insulin autoantibody, ${ }^{9-18}$ but previous studies have not been comprehensive or focused specific insulins.

In the present study, we examined whether medications for diabetes are risk factors for insulin autoantibody. Especially, we examined the associations between various types of insulin (i.e., human insulins, human insulin analogues, and protamine-containing insulins) and insulin autoantibody by performing a case-control study.

\section{Materials and Methods}

\section{Patients and study design}

From April 2005 to March 2010, insulin autoantibody (reference range, 0-10\%) was measured 273 total times in 217 patients in our hospital. Insulin autoantibody was measured when medical doctors suspect that patients may have insulin autoantibody. In some patients, insulin autoantibody was measured for the purpose of monitoring.

Insulin autoantibody was determined to be positive (greater than 10\%) 53 times in 19 patients. These 19 patients were included as the cases in our case-control study. Insulin autoantibody was found to be negative (0-10\%) 220 times in 198 patients. We included these 198 patients as the controls for the case-control study. For the case-control study, we listed patients' backgrounds in terms of age, gender, and diabetes [type 1 diabetes mellitus (T1DM), type 2 diabetes mellitus (T2DM), or no diabetes]. In addition, we listed oral hypoglycemic agents (OHAs) and insulins used by patients prior to measuring their levels of insulin autoantibody.

\section{Medications}

The medicinal products manufactured by Novo Nordisk Pharma Ltd. (Tokyo, Japan) were as follows: human insulin of regular type was denoted as Insulin R (Novo); human insulin of
Correspondence: Hiroyuki Kinoshita, Department of Internal Medicine, Tokyo Metropolitan Bokutoh Hospital 4-23-15, Koutohbashi, Sumida-ku, Tokyo 130-8575, Japan. Tel. +81.336336151 - Fax: +81.336336173 E-mail: hkinoshita-tky@umin.ac.jp

Key words: insulin autoantibody, protamine, aspart, glargine, human insulin analogues.

Acknowledgements: the authors would thank BML Inc. (Tokyo, Japan) for performing accurate measurements.

Conflict of interests: the authors report no conflicts of interests.

Received for publication: 30 September 2012. Revision received: 23 November 2012.

Accepted for publication: 27 November 2012.

This work is licensed under a Creative Commons Attribution NonCommercial 3.0 License (CC BYNC 3.0)

(C) Copyright H. Kinoshita et al., 2013

Licensee PAGEPress, Italy

Endocrinology Studies 2013; 3:e3

doi:10.4081/es.2013.e3

neutral protamine Hagedorn (NPH) type was denoted as Insulin N (Novo); biphasic insulin composed of 30\% Insulin R (Novo) and 70\% Insulin $\mathrm{N}$ (Novo) was denoted as Insulin 30 (Novo); the human insulin analogue of Pro28Asp, which is a rapid-acting type, was denoted as Aspart; biphasic insulin composed of $30 \%$ Aspart and $70 \%$ protamine-Aspart was denoted as Aspart 30; and the human insulin analogue of Lys29myristic acid and Thr30None, which is a long-acting type, was denoted as Detemir.

The medicinal products manufactured by Eli Lilly Japan K.K. (Hyogo, Japan) were as follows: human insulin of regular type was denoted as Insulin R (Lilly); human insulin of NPH type was denoted as Insulin N (Lilly); biphasic insulin composed of $30 \%$ Insulin R (Lilly) and $70 \%$ Insulin N (Lilly) was denoted as Insulin 30 (Lilly); the human insulin analogue of Pro28Lys and Lys29Pro, which is a rapid-acting type, was denoted as LisPro; and biphasic insulin composed of $50 \%$ LisPro and $50 \%$ protamine-LisPro was denoted as LisPro 50.

The medicinal product manufactured by Sanofi-aventis K.K. (Tokyo, Japan) was the human insulin analogue of Asn21Gly and ThrC-terminalArgArg, which is a long-acting type, and was denoted as Glargine.

All OHAs were summarized as OHAs.

\section{Insulin autoantibody measurement}

Insulin autoantibody was measured at BML Inc. (Tokyo, Japan) using Insulin Antibody Kit YAMASA® (YAMASA CORPORATION, Chiba, 
Japan). This second generation assay kit uses human recombinant insulin to detect antibody, such that the kit detects human insulin autoantibody. ${ }^{19}$

\section{Statistical analysis}

For continuous variables, Student's unpaired t-tests were performed. For categorical variables, Fisher's exact tests were performed. The odds ratio and its 95\% confidence interval (CI) were calculated with the Mantel-Haenszel method. The adjusted odds ratio [ (adjusted by age, gender, and disease (T1DM, T2DM, and no diabetes)] and its 95\% CI were calculated with logistic regression analysis. Significance was defined as $\mathrm{P}<0.05$ (equal to Odds ratio does not contain 1.0). All statistical procedures were performed with SAS software (SAS Institute Inc., Cary, NC, USA).

\section{Results}

\section{The backgrounds of the patients}

We performed a case-control study to examine the associations between various diabetesrelated medications and insulin autoantibody. The backgrounds of the patients included in this study are shown in Table 1. By chance, the ages $(\mathrm{P}=0.515)$ and genders $(\mathrm{P}=1.000)$ were not significantly different between the case and control groups. In case group, the number of T1DM, T2DM, and no diabetes were 7, 11, and 1 , respectively. In control group, the number of T1DM, T2DM, and no diabetes were 23, 140 , and 35 , respectively. The distribution difference of T1DM, T2DM, and no diabetes was statistically significant between the case and control groups $(\mathrm{P}=0.011)$; in case group, patients with diabetes, especially those with T1DM, were predominantly observed. Of the various medications taken by the patients, OHAs were not risk factors for insulin autoantibody; the odds ratio was 0.0 . In contrast, insulin use was a significant risk factor for insulin autoantibody; the odds ratio $(95 \% \mathrm{CI})$ was determined to be 56.3 (7.3-432.5). Based on these results, we subsequently examined the associations between the types of insulin and insulin autoantibody. For the purpose of screening suspected insulins, we investigated the single use of insulin and the combination use of insulin. Then, we examined the associations between suspected insulins and insulin autoantibody.

\section{Single use of insulin}

The results of the associations between the types of insulin and insulin autoantibody are summarized in Table 2. Analysis of single use of insulin (Table 2) revealed that Insulin $R$ (Novo) and Insulin R (Lilly) were not risk fac-
Table 1. Background of patients.

\begin{tabular}{lcccc} 
& Case & Control & P value & Odds ratio (95\% CI) \\
Number & 19 & 198 & - & - \\
Age & $55.8 \pm 21.8$ & $52.3 \pm 22.5$ & 0.515 & - \\
\hline Gender (\% male) & 57.9 & 60.01 & 1.000 & - \\
Type of diabetes & & & 0.011 & \\
$\quad$ T1DM & 7 & 23 & & 0.00 \\
$\quad$ T2DM & 11 & 140 & & \\
$\quad$ No diabetes & 1 & 35 & & \\
\hline Oral hypoglycemic agent & & & & \\
$\quad$ Yes & 0 & 42 & & \\
$\quad$ No & 19 & 126 & & \\
Insulin use & & & & \\
Yes & 18 & 48 & & \\
$\quad$ No & 1 & 150 & & \\
\hline
\end{tabular}

Table 2. The associations between the types of insulin and insulin autoantibody (single use of insulin).

\begin{tabular}{|c|c|c|c|}
\hline Insulin & Case & Control & Odds ratio $(95 \% \mathrm{CI})$ \\
\hline $\begin{array}{l}\text { Insulin R (Novo) } \\
\text { Yes } \\
\text { No }\end{array}$ & $\begin{array}{c}0 \\
19\end{array}$ & $\begin{array}{c}4 \\
194\end{array}$ & 0.00 \\
\hline $\begin{array}{l}\text { Insulin R (Lilly) } \\
\text { Yes } \\
\text { No }\end{array}$ & $\begin{array}{c}0 \\
19\end{array}$ & $\begin{array}{c}2 \\
196\end{array}$ & 0.00 \\
\hline $\begin{array}{l}\text { Insulin } 30 \text { (Novo) } \\
\text { Yes } \\
\text { No }\end{array}$ & $\begin{array}{c}7 \\
12\end{array}$ & $\begin{array}{c}7 \\
191\end{array}$ & $15.9(4.8-52.8)$ \\
\hline $\begin{array}{l}\text { Insulin } 30 \text { (Lilly) } \\
\text { Yes } \\
\text { No }\end{array}$ & $\begin{array}{c}1 \\
18\end{array}$ & $\begin{array}{c}0 \\
198\end{array}$ & Infinity \\
\hline $\begin{array}{l}\text { Insulin N (Novo) } \\
\text { Yes } \\
\text { No }\end{array}$ & $\begin{array}{c}1 \\
18\end{array}$ & $\begin{array}{c}1 \\
197\end{array}$ & $10.9(0.7-182.4)$ \\
\hline $\begin{array}{l}\text { Insulin N (Lilly) } \\
\text { Yes } \\
\text { No }\end{array}$ & $\begin{array}{c}0 \\
19\end{array}$ & $\begin{array}{c}1 \\
197\end{array}$ & 0.00 \\
\hline $\begin{array}{c}\text { Aspart } \\
\text { Yes } \\
\text { No }\end{array}$ & $\begin{array}{c}0 \\
19\end{array}$ & $\begin{array}{c}4 \\
194\end{array}$ & 00.00 \\
\hline $\begin{array}{l}\text { Aspart } 30 \\
\text { Yes } \\
\text { No }\end{array}$ & $\begin{array}{c}4 \\
15 \\
\end{array}$ & $\begin{array}{c}4 \\
194\end{array}$ & $12.9(2.9-56.9)$ \\
\hline $\begin{array}{c}\text { LisPro } \\
\text { Yes } \\
\text { No }\end{array}$ & $\begin{array}{c}0 \\
19\end{array}$ & $\begin{array}{c}2 \\
196\end{array}$ & 0.00 \\
\hline $\begin{array}{c}\text { LisPro } 50 \\
\text { Yes } \\
\text { No }\end{array}$ & $\begin{array}{c}0 \\
19\end{array}$ & $\begin{array}{c}2 \\
196\end{array}$ & 0.00 \\
\hline $\begin{array}{l}\text { Detemir } \\
\text { Yes } \\
\text { No }\end{array}$ & $\begin{array}{c}0 \\
19\end{array}$ & $\begin{array}{c}1 \\
197\end{array}$ & 0.00 \\
\hline $\begin{array}{c}\text { Glargine } \\
\text { Yes } \\
\text { No }\end{array}$ & $\begin{array}{c}0 \\
19\end{array}$ & $\begin{array}{c}1 \\
197\end{array}$ & 0.00 \\
\hline
\end{tabular}

Insulin R, human insulin of regular type; Insulin N, human insulin of neutral protamine Hagedorn (NPH) type; Insulin 30, biphasic insulin composed of 30\% Insulin R and 70\% Insulin N; Aspart, human insulin analogue of Pro28Asp; Aspart 30, biphasic insulin composed of 30\% Aspart and 70\% protamine-Aspart. Detemir; human insulin analogue of Lys29myristic acid and Thr30None. LisPro, human insulin analogue of Pro28Lys and Lys29Pro. LisPro 50, biphasic insulin composed of 50\% LisPro and 50\% protamine-LisPro. Glargine, human insulin analogue of Asn21Gly and ThrC-terminalArgArg. Novo, Novo Nordisk Pharma Ltd. (Tokyo, Japan). Lilly; Eli Lilly Japan K.K. (Hyogo, Japan). 
tors for insulin autoantibody, as both odds ratios were 0.0 . In contrast, both Insulin 30 (Novo) and Insulin 30 (Lilly) were significant risk factors for insulin autoantibody; the odds ratios were 15.9 (4.8-52.8) and infinity, respectively. In addition, Insulin N (Novo) was determined to be a possible risk factor; the odds ratio was 10.9 (0.7-182.4). Based on these results, we deduced that the NPH types of insulin are risk factors for insulin autoantibody.

Aspart was not a risk factor for insulin autoantibody, but Aspart 30 was determined to be a significant risk factor and had an odds ratio of 12.9 (2.9-56.9). In summary, all 13 of 13 (100\%) insulins that were used prior to the presence of insulin autoantibody were of the protamine-containing type: NPH type or protamine-insulin. These results indicate that protamine-containing insulins are risk factors for insulin autoantibody. LisPro, LisPro 30, Detemir, and Glargine were not risk factors for insulin autoantibody, although the user numbers of these medications were consistently small (less than or equal to 2 ).

\section{Combination use of insulin}

Based on our analysis of the combination use of insulin (Table 3$), 3$ of 5 (60.0\%) cases of insulin combinations included protamine-containing types: Insulin R (Novo) and Insulin N (Novo), Aspart 30 and Insulin N (Novo), and LisPro and Insulin N (Lilly). The other 2 of 5 (40.0\%) cases involved the insulin combination of Aspart and Glargine; the odds ratio was 5.7 (1.0-33.4). Based on the results of both the single (Table 2) and combination use of insulin (Table 3), 16 of 18 (88.9\%) insulins associated with insulin autoantibody were of the protamine-containing type, and the other 2 (11.1\%) were of the type of human insulin analogues: Aspart and Glargine. Therefore, we suspected that protamine-containing insulin, Aspart, and Glargine were associated with insulin autoantibody, and included them in further analyses.

\section{The associations between suspected} insulins and insulin autoantibody

As for the insulins implicated in the presence of insulin autoantibody (Table 4), the odds ratio and adjusted odds ratio for protamine-containing insulin were determined to be 35.3 (9.6129.5) and 29.6 (7.6-115.4), respectively. The odds and adjusted odds ratios for Aspart-containing insulin (Aspart or Aspart 30) were 6.2 (2.2$17.9)$ and 3.8 (1.2-12.0), respectively. The odds and adjusted odds ratios for Glargine were 3.2 (0.6-16.7) and $1.3(0.2-8.3)$, respectively.

Since 5 of 7 (71.4\%) cases of Aspart-containing insulin were Aspart 30, it remained unclear whether insulin autoantibody was derived from Aspart or protamine-Aspart. Thus, we performed a subpopulation analysis that exclu-
Table 3. The associations between the types of insulin and insulin autoantibody (combination use of insulin).

\begin{tabular}{|c|c|c|c|}
\hline Insulin & Case & Control & Odds ratio $(95 \% \mathrm{CI}$ \\
\hline Insulin R (Novo) - Insulin 30 (Novo) & & & 0.00 \\
\hline Yes & 0 & 1 & \\
\hline No & 19 & 197 & \\
\hline Insulin R (Lilly) - Insulin 30 (Lilly) & & & $\mathrm{N} / \mathrm{A}$ \\
\hline Yes & 0 & 0 & \\
\hline No & 19 & 198 & \\
\hline Insulin R (Novo) - Insulin N (Novo) & & & $2.67(0.3-25.4)$ \\
\hline Yes & 1 & 4 & \\
\hline No & 18 & 194 & \\
\hline Insulin R (Lilly) - Insulin N (Lilly) & & & 0.00 \\
\hline Yes & 0 & 1 & \\
\hline No & 19 & 197 & \\
\hline Insulin R (Novo) - Detemir & & & 0.00 \\
\hline Yes & 0 & 1 & \\
\hline No & 19 & 197 & \\
\hline Insulin R (Lilly) - Detemir & & & N/A \\
\hline Yes & 0 & 0 & \\
\hline No & 19 & 198 & \\
\hline Insulin R (Novo) - Glargine & & & 0.00 \\
\hline Yes & 0 & 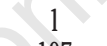 & \\
\hline No & 19 & 197 & \\
\hline Insulin R (Lilly) - Glargine & & & N/A \\
\hline Yes & 0 & 0 & \\
\hline No & 19 & 198 & \\
\hline Aspart - Aspart 30 & & & 0.00 \\
\hline Yes & 0 & 1 & \\
\hline No & 19 & 197 & \\
\hline Aspart - Insulin N (Novo) & & & 0.00 \\
\hline Yes & 0 & 3 & \\
\hline No & 19 & 195 & \\
\hline Aspart 30 - Insulin N (Novo) & & & infinity \\
\hline $\begin{array}{l}\text { Yes } \\
\text { No }\end{array}$ & $\begin{array}{c}1 \\
18\end{array}$ & $\begin{array}{c}0 \\
198\end{array}$ & \\
\hline
\end{tabular}

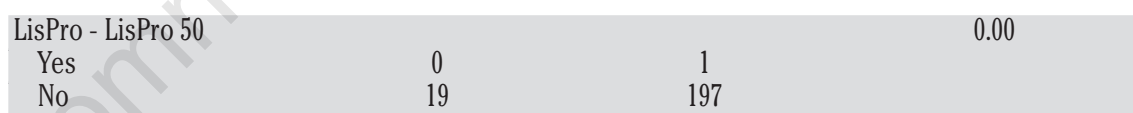

\begin{tabular}{lccc}
\hline LisPro - Insulin N (Lilly) & & & infinity \\
Yes & 1 & 0 & \\
No & 18 & 198 &
\end{tabular}

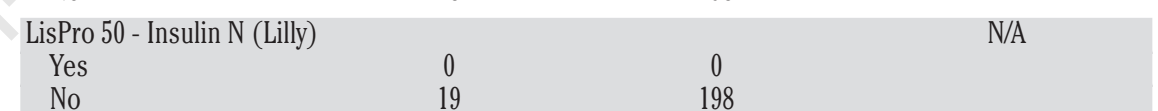

\begin{tabular}{lccc}
\hline Aspart - Detemir & 0 & 1 & 0.00 \\
Yes & 19 & 197 & \\
No & 2 & 4 & $5.7(1.0-33.4)$ \\
Aspart - Glargine & 17 & 194 & \\
$\quad$ Yes & & & N/A \\
No & 0 & 0 & \\
\hline LisPro - Detemir & 19 & 198 & 0.00 \\
$\quad$ Yes & & & \\
No & 0 & 1 & \\
LisPro - Glargine & 19 & 197 & \\
Yes & & & \\
No & & & \\
\hline
\end{tabular}

Insulin R, human insulin of regular type; Insulin N, human insulin of neutral protamine Hagedorn (NPH) type; Insulin 30, biphasic insulin composed of 30\% Insulin R and 70\% Insulin N; Aspart, human insulin analogue of Pro28Asp; Aspart 30, biphasic insulin composed of 30\% Aspart and 70\% protamine-Aspart. Detemir; human insulin analogue of Lys29myristic acid and Thr30None. LisPro, human insulin analogue of Pro28Lys and Lys29Pro. LisPro 50, biphasic insulin composed of 50\% LisPro and 50\% protamine-LisPro. Glargine, human insulin analogue of Asn21Gly and ThrC-terminalArgArg. Novo, Novo Nordisk Pharma Ltd. (Tokyo, Japan). Lilly; Eli Lilly Japan K.K. (Hyogo, Japan). 
des patients who had used protamine-containing insulins in order to eliminate the effects of protamine-containing insulins. Then, we evaluated the effects of Aspart and Glargine. These results are summarized in Table 5 .

The odds ratio for Aspart was 36.2 (2.9438.0), whereas the adjusted odds ratio was 74.6 (0.7-7691.1). The odds ratio for Glargine was 47.1 (3.8-584.0), and the adjusted odds ratio was 74.6 (0.7-7795.2).

In all population analyses, the ratio of the number of cases/controls was 19/198 $=0.096$ $<0.10$. In the subpopulation analysis, the ratio of the number of cases/controls was $3 / 172=0.017<0.10$. Therefore, the odds ratios calculated in this case-control study are approximate values of risk ratios for insulin autoantibody. ${ }^{20}$

\section{Discussion}

In the present study, we showed that insulin injection is a strong risk factor for patients presenting insulin autoantibody. However, human insulins without protamine were not risk factors. As for the suspected insulins, the protamine-containing insulins were strong risk factors. As for Aspart and Glargine, some of the odds ratios were significant but the numbers of these users were small, thus we considered that they are possible risk factors.

In past years, porcine and bovine insulins have been used for treating diabetes, and have led to patient development of many immunological problems, including anaphylaxis and insulin autoantibody. ${ }^{4}$ As causes of these problems, impurities or additives in insulin preparations and amino acids substitution(s) among species have been considered, ${ }^{4}$ which are further described below.

\section{Impurities and additives}

Porcine and bovine insulins are extracted and manufactured from the pancreas tissue of these respective animals. ${ }^{3}$ Therefore, various other hormones, such as glucagon, somatostatin, and vasoactive intestinal peptide, have been found to contaminate in these preparations as impurities.3,4 Furthermore, various additives have also been used in insulin preparations to make them long-acting; for example, protamine-supplemented insulins are used for this strategy. ${ }^{3,4}$ It has been shown that both impurities and additives can be immunogenic. ${ }^{3,4}$ However, after the appearance of human insulin, the problem of impurity disappeared because human insulin is not made from the human pancreas. On the other hand, the problem of additives still exists. In particular, antibody to protamine in patients treated with protamine-containing insulins has been reported. ${ }^{6,7}$ Further, two such studies have shown that 8 of 9 patients (88.9\%) and 4 of 6 patients (66.7\%) who were positive for protamine antibody also had insulin antibody. ${ }^{6,7}$ Furthermore, 6 of 15 (40\%) patients who were negative for protamine antibody had insulin antibody. ${ }^{?}$

In the present study, we also found that protamine-containing insulins were strong risk factors for the presence of insulin autoantibody, which is consistent with the results from the aforementioned reports. Thus, it seems that medical practitioners should choose protamine-free long-acting insulins, such as Detemir or Glargine. The developments of additives other than protamine are awaited to prevent protamine-induced insulin autoantibody.

\section{Amino acid substitutions}

There is 1 amino acid difference between human insulin and porcine insulin, whereas there are 3 amino acids that are different between human insulin and bovine insulin.,21 It was reported that $14 \%$ of patients who used human insulin had insulin antibody, whereas $29 \%$ of patients who used porcine insulin had insulin antibody.22 In addition, it was shown that the percentage of individuals who remained insulin antibody-free at 12 months was $56 \%$ patients treated with human insulin, and $40 \%$ patients treated with porcine insulin. ${ }^{23}$ It has also been reported that bovine insulin is more immunogenic than porcine insulin. ${ }^{24}$ In the United Kingdom, where bovine insulin was predominantly used, the antibody titers of individuals were relatively high compared with those in individuals from Scandinavia, where porcine insulin was predominantly used. ${ }^{4}$ Thus, the most immunogenic insulin is apparently bovine insulin, followed by porcine insulin, and then human insulin. These differences in immunogenicity may be due to differences in the numbers of amino acid substitution(s) in the different species.

All human insulin analogues have amino acid substitution(s), therefore, they also can be more immunogenic than human insulin. Some studies have compared the immunogenicity of human insulin analogues to that of human insulin.9-18 In detail, 9 of these studies examined rapid-acting types of insulin, and a single study examined a long-acting type of insulin. In 6 of the 9 studies on rapid-acting types of insulin, all patients received protamine-containing insulins for basal insulin.9-14 In the other 3 studies on rapid-acting types of insulin, patients received protamine-containing insulin or ultralente insulin (protaminefree animal insulin).15-17 Some of studies reported that human insulin analogues increase insulin antibody, though not statistically significant.9,10,13,14 Since protamine-containing insulins and animal insulins were risk factors for the presence of insulin autoantibody, ${ }^{3-7,23,24}$ we speculate that, in the abovementioned pre-

Table 4. The associations between suspected insulins and insulin autoantibody (all patient).

\begin{tabular}{lccc}
\hline & Case & Control & $\begin{array}{c}\text { Odds ratio (95\% CI) } \\
\text { Adjusted odds ratio }\end{array}$ \\
$\begin{array}{l}\text { Protamine-containing insulin } \\
\text { Yes }\end{array}$ & 16 & 26 & $35.3(9.6-129.5)$ \\
$\quad$ No & 3 & 172 & $29.6(7.6-115.4)$ \\
Aspart-containing insulin & 7 & 17 & $6.2(2.2-17.9)$ \\
Yes & 12 & 181 & $3.8(1.2-12.0)$ \\
No & & & \\
Glargine & 2 & 7 & $3.2(0.6-16.7)$ \\
Yes & 17 & 191 & $1.3(0.2-8.3)$ \\
No & & & \\
\hline
\end{tabular}

Adjusted odds ratio; adjusted by age, gender, and disease (TIDM, T2DM, and no diabetes). Aspart; human insulin analogue of Pro28Asp. Glargine; human insulin analogue of Asn21Gly and ThrC-terminalArgArg.

Table 5. The associations between suspected insulins and insulin autoantibody (patients without using protamine-containing insulins).

\begin{tabular}{lccc} 
Insulin & Case & Control & $\begin{array}{c}\text { Odds ratio (95\% CI) } \\
\text { Adjusted odds ratio }\end{array}$ \\
$\begin{array}{cccc}\text { Aspart } \\
\text { Yes }\end{array}$ & & $36.2(2.9-438.0)$ \\
No & 2 & 163 & $74.6(0.7-7691.1)$ \\
Glargine & 1 & 7 & $47.1(3.8-584.0)$ \\
Yes & 2 & 165 & $74.6(0.7-7795.2)$ \\
No & 1 & & \\
\hline
\end{tabular}

Adjusted odds ratio; adjusted by age, gender, and disease (T1DM, T2DM, and no diabetes). Aspart; human insulin analogue of Pro28Asp. Glargine; human insulin analogue of Asn21Gly and ThrC-terminalArgArg. 
vious studies, ${ }^{9-17}$ the effects of protamine-containing insulins and animal insulins on insulin autoantibody may have hidden the effects of human insulin analogues on insulin autoantibody. Indeed, in our present study, the odds ratios for Aspart and Glargine were increased after excluding patients that used protaminecontaining insulin from analysis (Table 5). In a single study on a long-acting type of insulin (Glargine), ${ }^{18}$ no increase of insulin antibody was reported, but further details were not provided.

In the present study, human insulin analogues except Aspart and Glargine were not risk factors. However, since the numbers of users for human insulin analogues except Aspart and Glargine were small, significant effects for insulin autoantibody may have been missed because of the insufficient power.

\section{Recommended therapeutic strategy for prevention of insulin autoanti- body}

Based on the present study, the following therapeutic strategies may be preferable for preventing insulin autoantibody. For T1DM patients, human insulin of regular type (t.i.d.) and human insulin analogues of the longacting type (v.d.S.) may be preferable. These prescriptions do not include protamine-containing insulins. For T2DM patients, diet, exercise, and OHAs should be used as much as possible to avoid using insulin. When T2DM patients must use insulin, the same insulins described above for T1DM may be preferable.

\section{The limitations in the present study}

The limitations in the present study are as follows. First, the number of patients with insulin autoantibody is 19 . The results of the present study therefore may not reproducible. Second, the present study includes biases that observed in case-control study. A prospective study, such as cohort study will be preferable. Third, the patients in the present study are Japanese; therefore, the generalization of the results to other population is not verified. Further studies will be required to examine the associations between the types of insulin and insulin autoantibody in other population.

\section{Conclusions}

After the 1980s, the presence of insulin autoantibody was decreased as a consequence of improvements in the purity of insulin preparations and the development of human insulin. However, the present study indicates that both additives and amino acids substitution(s) may lead to the presence of insulin autoantibody; the problems of immunogenicity of insulin preparations still exist to date. To decrease the problem of insulin antibody, avoiding the use of protamine-containing insulins and avoiding the use of human insulin analogues might be preferable for the patients with diabetes.

\section{References}

1. Moisés RS, Sá JR, Chacra AR, Russo EM. Relationship between insulin antibodies and metabolic control in type I diabetes mellitus. Braz J Med Biol Res 1990;23:1243-52.

2. Livneh A, Avraham H, Bistritzer T, et al. Deleterious effect of anti-insulin antibodies on diabetes control. Isr J Med Sci 1990;26:11-5.

3. Fineberg SE, Kawabata TT, Finco-Kent D, et al. Immunological responses to exogenous insulin. Endocr Rev 2007;28:625-52.

4. Kurtz AB, Nabarro JD. Circulating insulinbinding antibodies. Diabetologia 1980;19:329-34.

5. Van Haeften TW. Clinical significance of insulin antibodies in insulin-treated diabetic patients. Diabetes Care 1989;12:6418.

6. Kurtz AB, Gray RS, Markanday S, Nabarro JD. Circulating IgG antibody to protamine in patients treated with protamine-insulins. Diabetologia 1983;25:322-4.

7. Ellerhorst JA, Comstock JP, Nell LJ. Protamine antibody production in diabetic subjects treated with NPH insulin. Am J Med Sci 1990;299:298-301.

8. Ottesen JL, Nilsson P, Jami J, et al. The potential immunogenicity of human insulin and insulin analogues evaluated in a transgenic mouse model. Diabetologia 1994;37:1178-85.

9. Mianowska B, Szadkowska A, Pietrzak I, et al. Immunogenicity of different brands of human insulin and rapid-acting insulin analogs in insulin-naïve children with type 1 diabetes. Pediatr Diabetes 2010;12:7884.

10. Boehm BO, Vaz JA, Brøndsted L, Home PD. Long-term efficacy and safety of biphasic insulin aspart in patients with type 2 diabetes. Eur J Intern Med 2004;15:496-502.

11. Holmberg H, Mersebach H, Kanc K, et al.Antibody response to insulin in children and adolescents with newly diagnosed Type 1 diabetes. Diabet Med 2008;25:7927.
12. Jovanovic L, Ilic S, Pettitt DJ, et al. Metabolic and immunologic effects of insulin lispro in gestational diabetes. Diabetes Care 1999,22:1422-7.

13. Dailey G, Rosenstock J, Moses RG, Ways K. Insulin glulisine provides improved glycemic control in patients with type 2 diabetes. Diabetes Care 2004;27:2363-8.

14. Raskin P, Guthrie RA, Leiter L, et al. Use of insulin aspart, a fast-acting insulin ana$\log$, as the mealtime insulin in the management of patients with type 1 diabetes. Diabetes Care 2000;23:583-8.

15. Fineberg NS, Fineberg SE, Anderson JH, et al. Immunologic effects of insulin lispro [Lys (B28), Pro (B29) human insulin] in IDDM and NIDDM patients previously treated with insulin. Diabetes 1996;45:1750-4.

16. Fineberg SE, Huang J, Brunelle R, et al. Effect of long-term exposure to insulin lispro on the induction of antibody response in patients with type 1 or type 2 diabetes. Diabetes Care 2003;26:89-96.

17. Garg SK, Anderson JH, Perry SV, et al. Long-term efficacy of humalog in subjects with Type 1 diabetes mellitus. Diabet Med 1999,16:384-7.

18. Pieber TR, Eugène-Jolchine I, Derobert E. Efficacy and safety of HOE 901 versus NPH insulin in patients with type 1 diabetes. The European Study Group of HOE 901 in type 1 diabetes. Diabetes Care 2003;23: 157-62.

19. Insulin Antibody Kit YAMASA® (YAMASA CORPORATION, Chiba, Japan). Available from: http://www.yamasa.com/shindan/ PDF/AINleaflet09-01.pdf. Accessed: March 2012.

20. Rothman JK, Greenland S, Lash LT. Modern Epidemiology. 3rd edition. Philadelphia: Lippincott Williams \& Wilkins; 2007. pp 111-127.

21. Reeves WG, Kelly U. Insulin antibodies induced by bovine insulin therapy. Clin Exp Immunol 1982;50:163-70.

22. Schernthaner G, Borkenstein M, Fink M, et al. Immunogenicity of human insulin (Novo) or pork monocomponent insulin in HLA-DR-typed insulin-dependent diabetic individuals. Diabetes Care 1983;6 Suppl 1:43-8.

23. Fineberg SE, Galloway JA, Fineberg NS, et al. Immunogenicity of recombinant DNA human insulin. Diabetologia 1983;25:4659.

24. Chance RE, Root MA, Galloway JA. The immunogenicity of insulin preparations. Acta Endocrinol Suppl (Copenh) 1976;205: 185-98. 